\title{
Cost-Benefit Analysis of Health Service
}

\author{
By Robert N. Grosse
}

ABSTRACT: "Where my health is concerned, cost is no object." The reply of the penniless man to an expensive specialist reflects a moral question. Should the costs of health services be a significant consideration in deciding upon governmental health policies and programs? The answer in my opinion is yes. Costs ought to be used in deciding the level of health activities versus other social goods and services, and in planning which health programs to support. The truly moral problem is not to distinguish between good and evil but rather to select appropriately among alternative goods. After arguing that consideration of cost is a moral imperative, the usefulness of cost-benefit analysis in framing the right questions and in improving the chances of moving in directions of social improvement is urged, and some limitations are noted. Finally, examples of the use of cost-effectiveness analysis in studying problems of disease control and maternal and child health are given.

Robert N. Grosse is Professor of Health Planning, School of Public Health, and Director of the Interdepartmental Program in Health Planning, the University of Michigan, Ann Arbor. An economist, Dr. Grosse holds degrees from Columbia and Harvard. He was Deputy Assistant Secretary for Planning and Evaluation at the Department of Health, Education, and Welfare before going to Michigan. 
$\mathrm{T}$ THE MEANING of cost, in a general sense, is that of sacrifice. Webster's Second International defines cost as ". . . whatever, as labor, self-denial, suffering, etc., is requisite to secure benefit."

In economic analysis, as employed in cost-benefit or cost-effectiveness studies, costs are benefits lost. They are the result of a decision to forego benefits that could otherwise be obtained. What we decide to do has as its costs those good things we cannot achieve because of the decision to apply our resources in a particular way. ${ }^{1}$

A decision to invest more of society's resources in health programs means that less will be invested in education, housing, transportation, national security, space exploration, or private consumption. The costs of the addition to health programs are the foregone benefits from the best mix of additions to these others. Whether the cost is worthwhile depends on our values and on our ability to estimate and evaluate the benefits from the various alternatives.

In deciding how we might best use resources in the field of health, the cost of an investment in research or hospital construction may be the benefits foregone in extending access to current health services. The cost of saving lives by expanding a tuberculosis control program is the lives that might be saved by expanding a cervical cancer program, if both cannot be done because the available resources are limited.

Ivan Illich has put this concept forcefully in regard to modernization:

1. For good discussions of economic cost, see James M. Buchanan, Cost and Choice (Chicago: Markham, 1969); R. H. Coase, "The Nature of Costs," in Studies in Cost Analysis, David Solomons, ed. (Homewood, Ill.: Richard D. Irwin, 1968), pp. 118-133; and Robert E. Bickner, "Concepts of Economic Cost," in Gene H. Fisher, Cost Considerations in Systems Analysis (New York: American Elsevier, 1971), pp. 24-62.
Each car which Brazil puts on the road denies fifty people good transportation by bus. Each merchandized refrigerator reduces the chance of building a community freezer. Every dollar spent in Latin America on doctors and hospitals costs a hundred lives. ... Had each dollar been spent on providing safe drinking water, a hundred lives could have been saved. ${ }^{2}$

If, then, the costs of a decision are those things we most prize-human life, reduction of suffering, enhancement of the quality of life, protection of the dependent-then consideration of such costs should be a serious element in such decisions.

Perhaps the preceding belabors the obvious. But the outraged reactions of many of those in the humanitarian professions to "setting a price on human life" results often from a misunderstanding of the true nature of costs as considerations in decision-making. The cost of saving a human life is not to be measured in dollars, but rather in terms of alternative lives to be saved or other social values sacrificed. A dramatic battle over the costs and benefits of alternative allocations of health resources took place in China in the past few years. A decision to shift physicians, nurses, and sanitarians to rural areas had great consequences in benefits lost to urban centers and to health professionals. $^{3}$

If the concept of economic cost is such a desirable one to apply, is it difficult in practice to do so? Of course it is. One difficulty is that the benefits we compare are measurable only in very different dimensions. Health programs may have

2. Ivan D. Illich, Celebration of Awareness (New York: Doubleday, 1970), p. 163.

3. Descriptions of events and issues are in various issues of Current Scene-Developments in Mainland China: "Mao's Revolution in Public Health," May 1, 1968; "The Mao-Liu Controversy over Rural Public Health," June 15, 1969 ; "Public Health Developments-Continued Focus on Farms," December 15, 1969. 
as ultimate benefits the reduction of premature death, reduction of disabling conditions, reduction in suffering, ability to function better socially and at given tasks. Resources expended on arthritis control may reduce pain and disablement, but will have little effect on mortality rates. Other programs, such as the artificial kidney or heart transplants, may have their primary effect in postponing death.

When we consider measuring health program costs in their effects on programs foregone in education or housing, the dimensions of benefit are even more difficult to compare.

The inability to measure benefits in commensurable units does not mean that costs (foregone benefits) cannot be estimated and compared. It does mean, however, that judgments and political processes must be used to make the choices. Cost analysis makes these decisions better informed, so that we know more about how social values may be best realized.

In the search for commensurability, attempts have been made to reduce benefits to a common denominator, usually dollars. But agreement on dollar values is unlikely.

The problem of incommensurability is only one in a long list of measurement difficulties. We lack knowledge of the outputs or benefits of past and existing programs and projects, let alone those of future programs which may be foregone. But if we recognize the necessity for cost (and therefore benefit) information, then we may put a higher value on evaluation and analysis of programs. The development of production functions to give us greater insight into relations among resources, techniques, and outputs is a high priority item for better decision-making."

4. The relation of analysis and political decisions is well discussed in Charles $L$. Schultze, The Politics and Economics of Pub-
To illustrate some of the problems of estimating costs and benefits of health programs, as well as their use in aiding budget decisions and legislative proposals, two studies done at the Department of Health, Education, and Welfare are summarized.

\section{Disease Control Programs}

One of the first analytical studies at the Department of Health, Education, and Welfare was one on disease control programs then under way. Considerable work had been done during the last ten years in estimating the economic costs of particular diseases. Among the best known of these are Rashi Fein's Economics of Mental Illness, Burton Weisbrod's Economics of Public Health (in which he estimated the costs of cancer, tuberculosis, and poliomyelitis), Herbert Klarman's paper on syphilis control programs, and Dorothy Rice's studies covering the international classification of diseases. A generation earlier, Dublin and Lotka's classic study explored the impacts of disease and disability and their relation to changes in earning power. The economic implications of disability were, of course, a matter of central interest in the area of workmen's compensation insurance. It was not surprising, then, that when systematic quantitative analysis of government programs and policies began to spread from defense to civilian applications, one of the first analytical studies was a study of disease-control programs.

HEW supports, or could support, a number of categorical disease control programs whose objectives are, or would be, to save lives or to prevent disability by controlling specific diseases. The study was therefore an attempt to answer the question: If additional money were to be allocated to disease

lic Spending (Washington: Brookings Institution, 1968), pp. 55-76. 
Table 1-Cancer Control Program 1966-1972

\begin{tabular}{|c|c|c|c|c|}
\hline & $\begin{array}{l}\text { Uterine } \\
\text { Cervix }\end{array}$ & Breast & $\begin{array}{l}\text { Head and } \\
\text { Neck }\end{array}$ & $\begin{array}{l}\text { Colon- } \\
\text { Rectum }\end{array}$ \\
\hline $\begin{array}{l}\text { Grant funds total } \\
\text { (in thousands of dollars) }\end{array}$ & $\$ 97,750$ & $\$ 17,750$ & $\$ 13,250$ & $\$ 13,300$ \\
\hline $\begin{array}{l}\text { Number of examinations } \\
\text { (in thousands) }\end{array}$ & 9,363 & 2,280 & 609 & 662 \\
\hline Cost per examination & $\$ 10.44$ & $\$ 7.79$ & $\$ 21.76$ & $\$ 20.10$ \\
\hline $\begin{array}{l}\text { Examinations researched } \\
\text { per case found }\end{array}$ & 87.5 & 167.3 & 620.2 & 496.0 \\
\hline Total cases found & 107,045 & 13,628 & 982 & 1,334 \\
\hline Cost per case found & $\$ 913$ & $\$ 1,302$ & $\$ 13,493$ & $\$ 9,970$ \\
\hline Total deaths a verted & 44,084 & 2,936 & 303 & 288 \\
\hline Cost per death averted & $\$ 2,217$ & $\$ 6,046$ & $\$ 43,729$ & $\$ 46,181$ \\
\hline
\end{tabular}

SoURCE: The Analysis and Evaluation of Public Expenditures: The PPB Sysiem, U. S. Congress, Joint Economic Committee, Subcommittee on Economy in Government, 1969.

control programs, which programs would show the highest payoff in terms of lives saved and disability prevented per dollar spent? The study defined disease liberally. Motor vehicle accidents were included, together with tuberculosis, syphilis, cancer, and arthritis.

These programs are not research activities but those in which a technology exists, and the problem is whether to put the same, more, or fewer federal funds behind these control programs to support activities in hospitals, states, and communities. The question addressed is where to allocate the resources available for this purpose.

Table 1 illustrates the approach to one set of diseases, cancer. HEW looked at cancer of the uterine cervix, breast, head and neck, and colon-rectum. Estimates were made of cost per examination and the probable number of examinations that would be required for each case found. From this was derived the number of cases that would be found for a given expenditure level, and estimates of the cost per case found. An estimate was made of the number of deaths that could be averted by the treatment following the detection of the cancer, and then the cost per death averted was calculated; this ranged from about $\$ 2,200$ in the case of cervical cancer up to $\$ 40,000$ to $\$ 45,000$ in the case of head-and-neck and colon-rectum cancer.

On the vertical axis of figure 1 are plotted the program costs; these include the cost of the treatment in addition to the federal detection program. On the horizontal axis, estimates of deaths averted are ordered by the increase in cost per death averted in each program. Segments of the curve identified for each disease cover the extent of the program which it was estimated could be mounted in the years 1968-1972 before running into sharply increasing costs. In concept, the cervical cancer curve is cut off where costs become higher than the breast cancer program, and so on. From this analysis one might say that if there is available only $\$ 50$ million, cervical cancer should get all the funds. If we have $\$ 115$ million, then breast cancer control programs look quite competitive. Head and neck and colonrectum cancer detection as subjects of major control programs did not look attractive when viewed in this context. The analysts recommended that these programs concentrate on research and development. 
Deaths Averted per Dollar Expended for Various Health/Safety Measures FIgURe 1-Cancer Programs

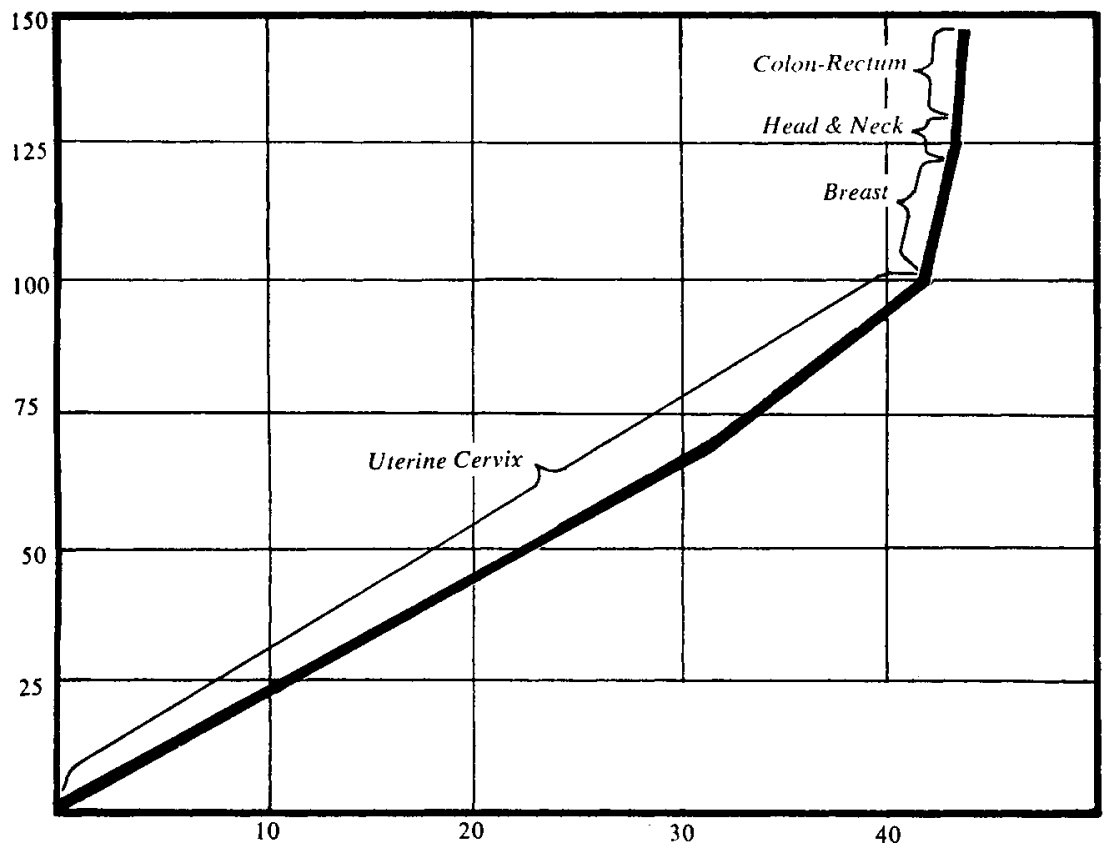

Figure 2-Cancer Programs Compared to Other Programs

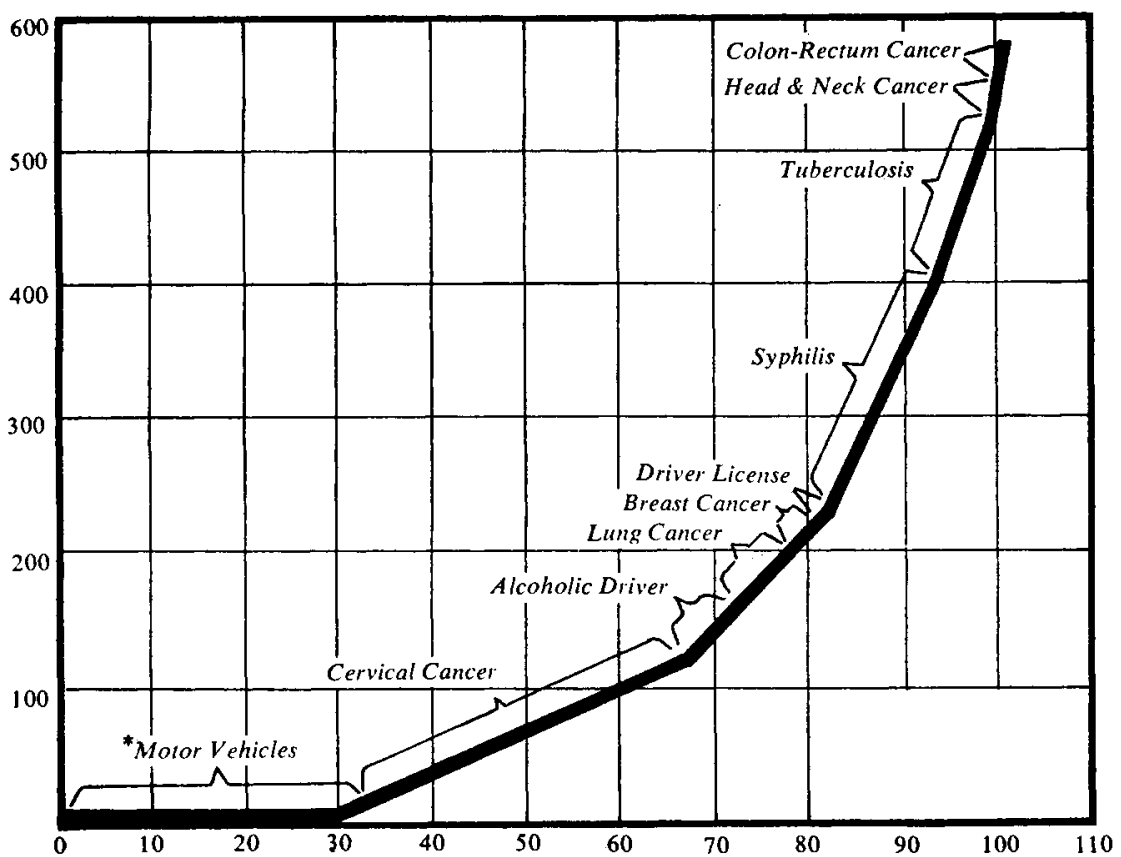

Horizontal: Deaths Averted-in thousands Vertical: Cost in millions of dollars Source: See Table 1. * Includes programs on use of seat belts, defensive driving, and reduction in pedestrian injuries. 
Figure 3-Dollar Saving in Cancer Programs Compared to Other Treatment Programs

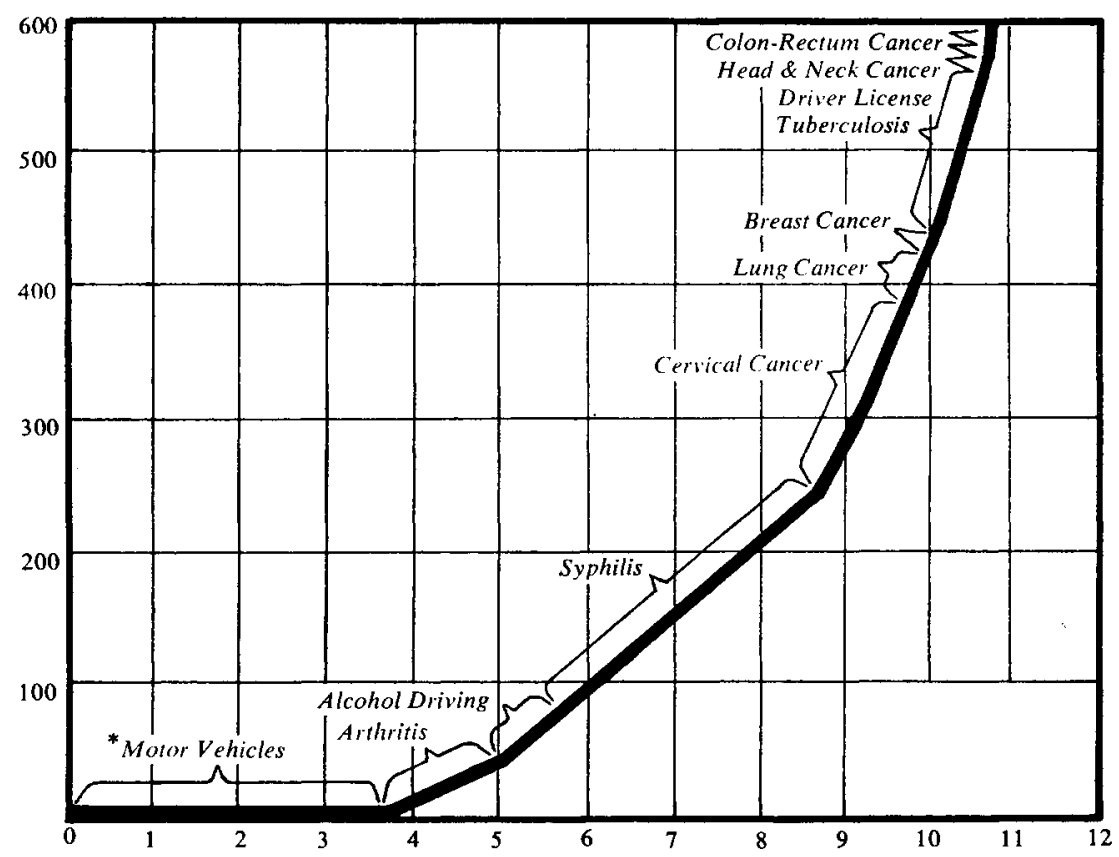

Horizontal: Savings in billions of dollars

Vertical: Program costs in millions of dollars

Source: See Table 1.

* Includes programs on use of seat belts, defensive driving, and reduction in pedestrian injuries.

The same kind of analysis was performed for each of the other, non-cancer programs studied (figure 2). There seemed to be a very high potential payoff for certain educational programs in motor vehicle injury prevention: trying to persuade people to use seatbelts, not to walk in front of a car, and so on. And then as we move up this curve, again ordered by cost of averting death, we begin adding the others.

This particular criterion, deaths averted, was not completely satisfactory. The number of fatalities attributed to arthritis was negligible, and so is not shown. Secondly, there was the question, did it matter who died? Did it matter whether it was a thirty-year-old mother or a forty-year-old father of a family or a seventy-five-year-old grand- father? On Figure 3, dollar-savings totaling the avoided medical treatments and a crude estimate of the average (discounted) lifetime earnings saved are plotted as a variable in place of deaths averted. There are two changes in results: Cervical cancer and syphilis control programs change places in priority order, and we are able to introduce the arthritis program.

These studies were not greeted with universal acclaim. Criticisms focused on a number of problems. First, with almost no exception the conclusions were based on average relationships. That is, the total benefits were divided by the total costs.

There was little evidence of what the actual impact of increasing or decreasing programs by small amounts might 
Treatment Costs Compared for Hypothetical Diseases

TABLE 2

\begin{tabular}{|c|c|}
\hline \multicolumn{2}{|c|}{ Disease A } \\
\hline EXPENDITURE & Laves Saved \\
\hline $\begin{array}{r}\$ 500,000 \ldots \\
1,000,000 .\end{array}$ & $\begin{array}{l}\ldots .360 \\
\ldots \ldots 465\end{array}$ \\
\hline \multicolumn{2}{|c|}{ Disease $B$} \\
\hline $\begin{array}{r}\$ 500,000 \ldots \\
1,000,000 .\end{array}$ & $\begin{array}{l}\ldots 200 \\
\ldots .270\end{array}$ \\
\hline
\end{tabular}

TABLE 3

\begin{tabular}{l}
\hline Expenditure \\
$\$ 1,000,000$ on Disease A $\ldots \ldots \ldots \ldots \ldots \ldots 465$ \\
$\$ 1,000,000$ on Disease B $\ldots \ldots \ldots \ldots \ldots \ldots 270$ \\
$\$ 1,000,000\left\{\begin{array}{c}\$ 500,000 \text { on } \\
\text { Disease A. } .360 \\
\$ 500,000 \text { on } \\
\text { Disease B . . 200 }\end{array}\right\} \ldots \ldots \ldots 560$
\end{tabular}

be. If we actually believed the average ratios to be valid at the margin, ought we not to put all our funds into the program with the highest benefit-cost or deaths-averted-per-dollar ratios?

Let me illustrate with a hypothetical example of how such marginal information might be used to determine the preferred mix of disease control programs. Assume that we can determine, as in tables 2 and 3, the number of lives saved by different expenditures on disease $\mathrm{A}$ and disease $\mathrm{B}$.

If we knew only the effect of spending $\$ 1$ million, we might opt for a program where all our money went toward controlling disease $\mathrm{A}$, by which we could save 465 lives instead of the 270 saved if we spent it all on disease B. Similarly, if we knew only the effects of programs using a half million dollars, we would probably prefer $A$, as we would save 360 rather than only 200 lives.

But if we knew the results for ex-
TABLE 4

\begin{tabular}{|c|c|}
\hline \multicolumn{2}{|c|}{ Disease A } \\
\hline EXPENDITURES & Lives Saved \\
\hline$\$ 100,000 \ldots$ & $\ldots 100$ \\
\hline$\$ 200,000 \ldots$ & .180 \\
\hline$\$ 300,000 \ldots$ & .250 \\
\hline$\$ 400,000$ & .310 \\
\hline$\$ 500,000 \ldots$ & .360 \\
\hline$\$ 600,000 \ldots$ & .400 \\
\hline$\$ 700,000 \ldots$ & .430 \\
\hline$\$ 800,000$. & .450 \\
\hline$\$ 900,000 \ldots$ & .460 \\
\hline$\$ 1,000,000 \ldots$ & .465 \\
\hline
\end{tabular}

Disease $B$

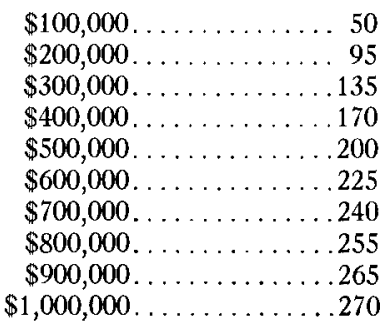

TABLE 5

\begin{tabular}{|c|c|c|}
\hline EXPENDITUKE & & Lives SAved \\
\hline$\$ 1,000,000$ & $\left\{\begin{array}{c}\$ 600,000 \text { on } \\
\text { Disease A. . } 400 \\
\$ 400,000 \text { on } \\
\text { Disease B . . } 170\end{array}\right.$ & $\ldots . .570$ \\
\hline
\end{tabular}

penditures of both a half million dollars and $\$ 1$ million in each program, we would quickly see that spending half our money in each program was better than putting it all in one, assuming we have $\$ 1$ million available.

But suppose we had still more discrete data, as in table 4 , which gives us the effect of each hundred thousand dollars spent on each control program. We could then spend the million dollars even more effectively, as in table 5.

The lack of marginal data resulted 
from both a lack of such data for most programs and a lack of economic sophistication on the part of the Public Health Service analysts who performed the studies. Despite the theoretical shortcomings, the results were useful when applied with some common sense.

Practical obstacles of existing commitments made it almost impossible to recommend reductions in any program. So the decisions dealt with the allocation of modest increments.

In the case of oral and colon-rectum cancer, the average cost per death averted seemed so high that the department recommended emphasis on research and development rather than on a control program to demonstrate and extend current technology.

In cervical cancer, investigation indicated a sizable number of hospitals in low socio-economic areas without detection programs which would be willing to establish these if supported by federal funds. The unit cost of increasing the number of hospitals seemed to be the same as that of those already in the program. Shifting the approach to reach out for additional women in the community would increase costs per examination but not so much as to change the relative position of this program. At most, it raised costs to about those of the breast cancer control program.

Despite the seemingly high potential payoff of some of the motor vehicle programs, there was considerable uncertainty about the success. As a consequence, recommendations were for small programs with a large emphasis on evaluation for use in future decisions. The same philosophy was applied to the arthritis program.

Programs were classified into categories by relative pay-off (deaths averted; savings) and certainty of result. Thus, a matrix of four possibilities might be drawn, as in figure 4 . Some of the programs falling within
FIGURE 4-Programs Classified by Magnitude and Certainty of Result

\begin{tabular}{|c|c|c|}
\hline & \multicolumn{2}{|c|}{ PAY-OFF } \\
\hline & $\mathrm{HIGH}_{\mathrm{I}}$ & Low \\
\hline CFRTAINTY & $\begin{array}{l}\text { Cervical } \\
\text { Cancer } \\
\text { Syphilis }\end{array}$ & $\begin{array}{l}\text { Colon-rectum } \\
\text { Cancer } \\
\text { Head and } \\
\text { Neck } \\
\text { Cancer }\end{array}$ \\
\hline Low & $\begin{array}{l}\text { Motor } \\
\text { Vehicle } \\
\text { Education } \\
\text { Arthritis }\end{array}$ & $\begin{array}{l}\text { Heart } \\
\text { Transplant }\end{array}$ \\
\hline
\end{tabular}

these possibilities are inserted for illustration.

In programs for which the pay-off looked very good, and with relative confidence in the calculations, recommendations for substantial increases in funding were made. Where the pay-off looked high but was rated with considerable uncertainty, as in educational programs to stimulate use of restraining devices in automobiles, modest funding was suggested with large evaluation components to buy more information. Where results looked relatively poor, it was recommended that no additions to program be made, and that investment might better be placed in additional research to develop improved screening techniques, epidemiological knowledge, or therapy.

The analyses and recommendations were fed into the decision-making process, which also considers existing commitments, the political situation, feasible changes in the rates of spending, the ability to get people moving on programs, and so on.

What resulted, then, was a setting of priorities for additional funding, based on the analytical results, judgment about their reliability, and practical considerations.

A second type of criticism of the analysis described above was concerned with the criteria, especially the calculation of benefits. They were considered 
inadequate in that they paid attention to economic productivity alone, and omitted other considerations. In particular, they were thought to discriminate against the old who might be past employment years, and women whose earnings were relatively low. It was also feared that the logic, if vigorously pursued, would penalize not only health programs for the aged such as the newly launched Medicare, but also programs aimed at assisting the poor, whose relative earning power is low by definition.

In actual practice in the programs studied, these concerns were only hypothetical. The programs for cervical and breast cancer, limited, of course, to women, seemed to be good. As for the poor, most of the programs considered, especially cervical cancer, syphilis, and tuberculosis, were directed primarily at them, and projects were usually located to serve low-income residents.

Another type of objection was raised not against the technique of analysis, but against its being done at all. Choices among diseases to be controlled and concern with costs of saving lives can be viewed as contrary to physicians' attitudes in the care of an individual patient. Yet, such decisions are made, analysis or no. Prior decisions on allocations to various health problems rested upon a combination of perception of the magnitude of the problem and the political strength organized to obtain funding, as in the National Tuberculosis Association.

The disease control cost-benefit analyses suggest that additional considerations are very relevant. Given scarce resources-and if resources are not scarce, there is no allocation problem-one ought to estimate the costs of achieving improvement in health. If we can save more lives by applying resources to a small problem-in numbers affected-rather than a large one, we ought to consider doing so.

\section{Maternal and Child Health Programs}

In regard to maternal and child-care programs, the stated goal was to make needed maternal and child health services available and accessible to all, in particular to all expectant mothers and children in health-depressed areas. Health-depressed areas could be characterized as areas with excessive infant mortality rates. There is no universal index of good or bad health among children. Two measurable areas were selected: mortality, and the prevalence of chronic handicapping conditions. Over a dozen possible programs aimed at reducing these were examined. On table 6, three selected programs addressed to the problem of coverage of maternal and child health are illustrated, two of them comprehensive programs of care to expectant mothers and children. This table shows the annual effects of spending the same amount of money, $\$ 10$ million a year, in different ways. The analysts examined comprehensive care programs covering up to age eighteen and up to age five, with estimates based on the best assumptions derived from the literature and advisers on the probabilities of prevention of maternal deaths, premature deaths, infant deaths, and mental retardation, and handicapping conditions prevented or corrected by age eighteen. They also looked at a program of early case-finding and assured treatment which focused on children at birth (aged four days) and again every other year until they were nine. Expending the same amounts, the money yields different results depending on where it is put. With respect to reduction of infant mortality, several other programs had higher payoffs than these. For example, a possible program of intensive-care units for highrisk newborns was estimated to reduce annually 367 deaths if we "put all our 
TABLE 6-Yearly Effects PER $\$ 10,000,000$ EXPENDED IN HEALTH-DEPRESSED AREAS

\begin{tabular}{|c|c|c|c|}
\hline & \multicolumn{2}{|c|}{ COMPREHENSIVE PROGRAMS } & \multirow{2}{*}{$\begin{array}{c}\text { CASE FINDING } \\
\text { OF TREATMENT } \\
0,1,3,7,7,9 \\
\text { years of age }\end{array}$} \\
\hline & to age 18 & to age 5 & \\
\hline Maternal deaths prevented & 1.6 & 3 & \\
\hline Premature births prevented & $100-250$ & $200-485$ & \\
\hline Infant deaths prevented & $40-60$ & $85-120$ & \\
\hline Mental retardation prevented & $5-7$ & $7-14$ & \\
\hline \multicolumn{4}{|l|}{$\begin{array}{l}\text { Handicaps prevented } \\
\text { or corrected by age } 18 \text { : }\end{array}$} \\
\hline Vision problems: All & 350 & 195 & 3,470 \\
\hline Amblyopia & 60 & 119 & 1,140 \\
\hline Hearing loss: All & 90 & 70 & 7,290 \\
\hline Binaural & 6 & 5 & 60 \\
\hline Other physical handicaps & 200 & 63 & 1,470 \\
\hline
\end{tabular}

Source : See Table 1.

eggs in one basket"; this would cost about $\$ 27$ thousand per infant death prevented. The programs shown cost about four times that amount, but they do other good things, too.

The HEW analysts also looked at programs with a given amount of money aimed at reducing the number of children who would have decayed and unfilled teeth by age eighteen (see table 7). Introducing fluoridation programs in communities which do not possess them, will, for the same amount of money ( $\$ 10$ million), give us close to 300,000 fewer children in this condition, compared to the 44,000 or 18,000 fewer in the other programs noted. Fluoridation looks like a very attractive program. It is so attractive that it could be inferred that a program as cheap as this is not being inhibited by lack of financial support by the federal government; there are other factors at work.

One other program, additional funds on family planning, looked like a very good way to reduce not only the number of infant deaths but also the rate of infant mortality in high-risk communities.

Despite the information difficulties, several conclusions emerged clearly from the study. Two of these conclusions resulted in new legislation being requested from Congress. First, it seemed clear that a program of early case-findings and treatment of handicapping conditions would have considerable pay-off. It was also clear that if the large number of children who do not now have access to good medical care were to be provided with pediatric services, an

TABLE 7-Reduction in Number of Children With Decayed TeETh per $\$ 10$ Million Expended

\begin{tabular}{|c|c|c|}
\hline TREATMENT & $\begin{array}{l}\text { APPROXIMATE } \\
\text { POPULATION } \\
\text { COVERED } \\
\text { (IN THOUSANDS) }\end{array}$ & $\begin{array}{c}\text { REDUCED } \\
\text { NUMBER OF } \\
\text { CHLDREN } \\
\text { (IN THOUSANDS) }\end{array}$ \\
\hline Fluoridation alone & 14,085 & 294 \\
\hline Comprehensive dental care with fluoridation & 729 & 44 \\
\hline Comprehensive dental care without fluoridation & 333 & 18 \\
\hline
\end{tabular}

Source: See Table 1. 
acute shortage of doctors would be precipitated. Ways have to be found to use medical manpower more efficiently. The Social Security Amendments of 1967 include provision for programs of early case-finding and treatment of children with handicapping conditions.

These condensed discussions of some of HEW's applications of cost-benefit analysis to disease-control and child health programs illustrate both the use- fulness and limitations of such analyses for decision-making. Issues are sharpened, and quantitative estimates are developed to reduce the decision-maker's uncertainty about costs and effects. Nevertheless, the multiplicity of dimensions of output and their basic incommensurabilities, both with costs and with the outputs of other claimants for public expenditure, still require the use of value judgments and political consensus. 